\title{
ETHICAL CHALLENGES OF USING VIDEO FOR QUALITATIVE RESEARCH AND ETHNOGRAPHY
}

\section{State of the art and guidelines}

\author{
Marina Everri, Maxi Heitmayer, Paulius Yamin-Slotkus, and \\ Saadi Lahlou
}

\section{Introduction}

Visual methods have been essential in ethnography from the start: the iconic ethnographer (or anthropologist) is pictured equipped with cameras and a notebook full of drawings. "Visual" refers to diverse methods of investigations based on the collection, analysis, dissemination of still (photography, drawings, paintings, etc.) or moving images (film, live performance) often associated with audio (e.g. video). But compared to the $16 \mathrm{~mm} \mathrm{B \& W}$ camera used in the seminal "Cinéma Vérité" of ethnographer Jean Rouch and sociologist Edgar Morin (Rouch and Morin 1961), which renewed the concept of "documentary", the increased affordability of high-quality equipment and the superior quality of video data compared to other forms of recording brought a "visual turn" (Rose 2014) in many social sciences. Additionally, the rich, visually appealing and seductive nature of video-based data can convey a strong sense of direct experience with the phenomena studied (Pea 1999). Therefore, research relying on visual methods as well as ethnography techniques based on video recordings have steadily increased over the last decade (Gubrium and Harper 2013; Pink et al. 2016). This raises new ethical challenges. Images pose specific ethical issues for research participants because they afford physical recognition of persons, spaces and places, and give the impression of an "objective depiction of reality" (de Laat 2004). Videos can provide confidential information on participants' habits and behaviours. The audio embedded in images puts participants' privacy at risk.

The issue is the following: techniques which aim at depicting or understanding generic aspects of behaviour for scientific purposes (where specific identity does not matter) nevertheless document behaviours on specific identifiable individuals (therefore making these specific individuals publicly accountable for their 
behaviour). This problem of course applies to many types of data in social science (or medicine), but the visual nature of the data makes anonymization especially challenging. As we discuss below, current guidelines, inspired by medicine, focus on anonymization - which may work for physiology but not for social behaviour - rather than on the actual problem which is the potential impact of public disclosure of personal behaviour.

Interestingly, the majority of ethical guidelines do not make specific distinctions between photographs and videos - most regulations apply to both. Therefore, we maintain here the usage of the term "visual" as we discuss the literature on the topic; we will then introduce specifications when referring to ethical issues pertaining to video.

This contribution proposes a comprehensive and consistent point of reference for unified guidelines on the ethical conduct of video-ethnography and qualitative research designs based on video data. The chapter includes four main sections. The first provides a systematic review of current research ethics guidelines to collect visual data with different populations (e.g., adults and children), institutions, and informal settings. The second highlights the main challenges and gaps concerned with a) researcher-researched rapport, b) informed consent, and c) participants' rights (anonymity, confidentiality, data ownership, and release). The third tackles prospective solutions including setting up the research in a way that fosters ethical behaviours by design. It is illustrated with exemplary cases. The fourth provides practical advice for an "ethical twist" towards participants on ethnographic visual research methods.

\section{Ethnography and visual research ethics guidelines: state of the art}

We carried out a systematic analysis of the literature to get a broad overview of ethical issues in relation to visual methods. Three databases (Scopus, Web of Science, Ebsco) were searched independently with the following combination of keywords: video + ethnography + ethic ${ }^{\star}$; visual ethnography + ethic ${ }^{\star}$; video research + ethic ${ }^{\star}$. This provided 54 references, including journal articles, handbooks, and book chapters; four in which ethics was peripheral were deleted. Current regulations and guidelines on visual research were found across different disciplines and institutional boards both in academic and non-academic institutions.

While most ethical issues regarding textual material can be solved using abbreviations, initials, pseudonyms, etc., scientific and institutional boards are still struggling with visual techniques. Very few publications (e.g. Kelly et al. 2013; Wiles et al. 2008) provided a comprehensive account of ethical issues in visual research, for example concerning privacy, researcher-participant rapport, and informed consent. The majority tackled methodological (18 references) and health issues (13 references), the latter comprising research carried out in psychotherapy, clinical psychology, medicine and nursing. Resources on health issues focused on sensitive environments, such as emergency interventions or 
patients with dementia. Four of them (Schuck and Kearney 2006; Winckler 2014; Derry et al. 2010; Hackling 2013) discussed visual methods and ethical issues in education; six addressed children (Aarsand 2016; Aarsand and Forsberg 2010; Robson 2011; Flewitt 2005; Heath, Hindmarsh, and Luff 2010; Mudaly 2015). In the latter case, they question the role of parents and guardians for informed consent, but do not mention informed assent for children. Lastly, a few papers connected visual ethics to the specific realms of anthropology (four: Eglinton 2013; de Laat 2004; Pope, De Luca, and Tolich 2013; Pink 2011) and sociology (four: Milne, Mitchell, and de Lange 2012; Prosser, Clark, and Wiles 2008; Salmons 2015; Papademas 2004).

The guidelines produced by scientific boards dwell on issues similar to scientific publications. The Association of Internet Researchers (Markham and Buchanan 2012), the American Anthropological Association (2001), the Association of Social Anthropologists of the UK (2011), the British Sociological Society (2017), or the International Visual Sociology Association (Papademas 2009) all provided recommendations on consent and results accessibility, harm and vulnerability, data management, and anonymity and confidentiality with emphasis on aspects consistent with the purposes of their specific scientific community.

Universities and other research institutions, such as the British Economic and Social Research Council (ESRC), often have dedicated research ethics committees. For example, the London School of Economics has a general Research Ethics Policy and Procedures document, a Code of Research Conduct and an Ethics Code (accompanied by an ethics guidance document). Researchers must complete a Research Ethics Review Form, which is the only document explicitly mentioning visual research, linked to potential confidentiality and anonymity issues (London School of Economics and Political Science 2019).

These guidelines conform with the recent EU General Data Protection Regulation (GDPR), put into place to guarantee the lawful, fair and transparent collection of personalised data. GDPR does not apply to anonymised data, but it is important to note that while pseudonymisation can be sufficient to anonymise certain types of data, the situation with visual data is more complicated. For example, a video showing a participant commuting to work, even with faces blurred, still shows their home and the work address, which can be identifiers.

In summary, the literature on research ethics seems to converge on general ethics guidelines concerned with participant data protection. Some scientific boards provide regulations on visual research, however without making specific reference to the collection, analysis, treatment and protection of video data as well as to the peculiarities of ethnographic research.

\section{From visual to video-research: critical aspects and literature gaps when using video}

We found ample criticism both for research institutions and ethics boards in almost every article we surveyed. The rigidity of formal ethics processes in academic 
institutions, by narrowly focusing on what regulation will allow (Wiles, Coffey, and Robinson 2010, 21) neglects crucial aspects embedded in qualitative and ethnographic inquiry. These are: the characteristics of researcher-researched rapport; procedures for achieving truly informed consent; the acknowledgement of participants' rights, namely researchers' measures taken to guarantee participants' anonymity, confidentiality, and data ownership and release. Across these aspects, the social and cultural particularities of research contexts play a key role and must be assessed and negotiated beforehand by researchers. These differences might determine, for example, the appropriateness of using video and photography techniques (Kelly et al. 2013), the general understanding that participants have of privacy, consent and data ownership, and what constitutes sensitive activities or images (Cox et al. 2014). For example, while filming breakfast is usually innocuous, documenting sexual practices may not be. Ethical guidelines rarely focus on the actual risk assessment of the disclosure, making it difficult if not impossible to record a football match played by children, while allowing recording of an identifiable adult describing or performing any behaviour as long as an "informed" consent is signed. Overall, we found consensus among social scientists that the "biomedical model", which has served as the basis for ethical guidelines for the social sciences, is deficient when applied to visual research, and ethnographic research more broadly (Atkinson 2009).

\section{Researcher-researched rapport}

There is a power imbalance between researchers and participants, related to status, knowledge, and nature of the relationship in which both parties are engaged (Carroll 2009). During the process of ethnographic data collection, however, the boundaries become "fuzzy" (Gubrium, Hill, and Flicker 2014). Many researchers point out that it becomes difficult to anticipate ethical issues with such a flexible researcher-researched relationship, making reflexive practice an ongoing concern throughout the research process (e.g. Blazek and Hrañová 2012; Cox et al. 2014). Reflexivity must not mean merely going beyond "deploying the method" (Carroll and Mesman 2018, 1151) and reflecting on one's practice as a researcher, but also being continuously aware of, and questioning the prescribed roles of researcher and researched, and their relationship. In consequence, taking the collected video as depicting a "hard reality" cannot be sufficient for truly reflexive practice; participants' voices must also be included during the interpretation of the data, creating a third voice, "which combines the view of the researcher and the researched" (Ruby 1991, 62).

\section{Informed consent}

Pre-formatted checklists distributed by institutional ethics boards, that usually are to be filled out prior to data collection, neither enable researchers to react adequately to issues arising during research, nor do they enable ethics boards to ensure 
adherence to ethical standards (e.g., Cox et al. 2014; Gubrium, Hill, and Flicker 2014). Rapidly progressing technologies in video-ethnographic research further complicate this issue: "many visual dilemmas emerge in specific contexts and cannot be resolved by appeal to higher principles and codes" (Clark, Prosser, and Wiles 2010, 90).

Achieving truly informed consent with checklists and by handing out paper forms prior to data collection, which is the standard procedure for most academic institutions (e.g. Gubrium, Hill, and Flicker 2014; Lenette et al. 2018), is not possible. In practice, evaluating whether the outcome potentially discloses things detrimental to participants is often difficult to assess before the visual material is presented in the results; at that stage sensible editing can make the material innocuous to individual participants; conversely awkward presentation can make innocuous material harmful.

In practice it is almost impossible to obtain informed consent from everyone that is captured in the video. Consider filming in shopping centres, airports or in the streets. Even providing information about the research project to those entering the video recorded place or space (a common practice in video-research) is often impracticable in natural contexts (Aarsand 2016). Moreover, in most ethnographic investigations, the researcher's level of control can be limited or voluntarily transferred to participants. For instance, the SEBE (Subjective Evidence Based Ethnography) research protocol is based on first-person video recordings; participants carry out the recordings and researchers are not with them in the field, whilst available remotely (Lahlou 2017; Lahlou, Le Bellu, and Boesen-Mariani 2015). Therefore, it is not possible to know in advance the detailed contents of recordings. Furthermore, as participants can review and download their films before handing them to the researcher in SEBE (precisely to make sure they are happy with the content disclosed), they could potentially share this content to third parties. That is true for most investigations where participants collect data themselves, such as story-telling using cameras (Gubrium and Harper 2013), video-tours (Demuth and Fatigante 2012) and self-recording with wearable devices (e.g., Kelly et al. 2013).

\section{Participants' rights: anonymity, confidentiality, data ownership and release}

Anonymity and confidentiality are long-established principles in social research practice (Wiles, Coffey, and Robinson 2010). However, visual material makes anonymisation problematic if not impossible (Clark, Prosser, and Wiles 2010). Furthermore, some participants might agree or want to have their personal information disclosed. Asking participants to participate in an ethnographic investigation using visual methods is "equivalent to requesting them to share with the world their insight and perspective" (Schembri and Boyle 2013, 1253).

The release of video materials is a sensitive issue: they might expose participants to stigma, discrimination, and other types of harm (Wiles et al. 2008; Gubrium, 
Hill, and Flicker 2014). Particularly important are the considerations around "where, why and by whom" (Gubrium, Hill, and Flicker 2014) are visual materials released. No data is confidential per se: we share sensitive data about our health with our doctor, about sexual preferences with our partner, financial details with our banker and so forth (Lahlou 2008). The context of where and to whom the material is published matters. As new technologies allow to easily capture, review, interpret, and share "too much information" (Mok, Cornish, and Tarr 2015), the issues of who controls and stores the data, who is the author or owner, who decides what to share and how have become central in visual research (Schuck and Kearney 2006; Heath, Hindmarsh, and Luff 2010; Cox et al. 2014). Often participants agree to share their videos with the research team but refuse publication of identifiable material beyond that trusted community. New technologies and devices (such as smartphones and digital video) mean that participants can have more control over research materials, but it also means that they may easily view, copy and share them (Mok, Cornish, and Tarr 2015). Additionally, as hinted above, it is difficult for participants to foresee the future implications of the existence of their data and, hence, to give informed consent beforehand (Aarsand 2016; Wiles, Coffey, and Robinson 2010). Failing to appropriately negotiate and acknowledge authorship and ownership of visual data might endanger the integrity of research and the confidence of participants in it (which impacts their insights, contributions, and future willingness to take part - see Cox et al. 2014).

Additionally, in video research there is the assumption that images are objective and can accurately represent "the reality" (de Laat 2004), more than text (Schuck and Kearney 2006). This "myth of film-as-reality" (de Laat 2004, 137) in research has been questioned: images are cultural constructs, and the same videotape can create in viewers different interpretations of the situation (Liegl and Schindler 2013; Rieken and Lahlou 2010).

\section{Prospective solutions for video ethnography methods}

The literature reviewed, beyond caveats and interdictions, provides practical advice for ethical visual research. Among these few it is agreed that "research ethics are contested, dynamic and contextual" (Prosser, Clark, and Wiles 2008, 3). Therefore, besides considering ethical regulations, it is crucial to understand the concrete situations in which ethics regulations are applied. The adoption of reflexive and collaborative approaches can serve this function (see Cox et al. 2014; Gubrium et al. 2014; Liegl and Schindler 2013; Schembri and Boyle 2013; Rose 2014).

\section{Researcher-researched rapport: situatedness, reflexivity, and collaboration}

"Because ethics are so embedded in the specific research contexts in which ethnographers work, like decisions about which visual research methods to employ in a project, ethical decisions cannot be concluded until the researcher is actually 
in the field" (Pink 2011, 11). As a result, a continuous reflexive approach paying attention to what is ethical in the participants, not just in the researchers' culture, is necessary.

Reminding researchers to think about general ethical standards regarding, for instance, privacy, anonymity, and voluntary informed consent is, thus, only the first step to truly ethical research. In a second step, contextual judgement and ongoing consent processes as outlined by Cicourel (1964) should be accommodated for in standard research ethics procedures (e.g. Carroll and Mesman 2018; Mok et al. 2015). Researchers should plan for, and actively manage and mitigate both the physical and psychological risks that visual research creates for participants (Pope, De Luca, and Tolich 2013; Schembri and Boyle 2013). Mok and colleagues recommend that an ongoing, participatory exchange with the public around the ethicality or acceptability of novel research methods be put into place (Mok, Cornish, and Tarr 2015, 320).

Collaborative approaches include both acquiring a deep knowledge of local contexts and their intrinsic power relations (Liegl and Schindler 2013; Schembri and Boyle 2013), as well as engaging in critical dialogues with participants about potential risks and harm and how to manage them (Cox et al. 2014; Schembri and Boyle 2013). This is particularly relevant when working with vulnerable populations such as children (Mudaly 2015) or exploring illegal activities (Gubrium, Hill, and Flicker 2014).

In our view, the efficacy of video ethnography as a research method depends on establishing a relationship of trust between the participant and the researcher (Lahlou 2006; 2011). It is a necessary condition for participants to disclose their thoughts to the researcher, engage in cooperative observation, and contribute to the interpretation of data (Lahlou, Le Bellu, and Boesen-Mariani 2015). Studies using SEBE, ${ }^{1}$ involving different participant cohorts in various settings (e.g. children and families, consumers, office workers, doctors and nurses, drivers, cooks, policemen, nuclear plant operators), consider participants as co-researchers (not "subjects") as they do not only collect the data, but also contribute to data interpretation by commenting on their own video recordings in a face to face interview with the researcher. This Replay Interview (RIW) confronts emic (informants') and etic (researchers') perspectives to find a description that is acceptable to both based on the joint review of the video evidence (Lahlou 2011). This form of democratic collaboration allows participants (of any age, gender, status) to feel empowered, and researchers to test their hypotheses and interpretations in vivo. While not all protocols include a phase of confronting the participants with the material and its interpretation, we suggest that discussing the (pre) final version of the visual material to be published, and its interpretation, with at least some of the participants is a major ethical safeguard. These conversations, if done in a pilot, will also inform the researcher on the actual ethical issues in that context, and impact the protocol. 


\section{Informed consent as a negotiation process}

In most cases researchers face the "impossibility of setting a-priori conditions about what participation will involve and what images might be filmed or photographed" (Wills et al. 2016, 481). There is agreement among ethnographers to consider consent as a process that requires negotiations with participants at different stages of the research. This can be done by negotiating consent prior and following the video recordings, or by opting for an ongoing consent negotiation to monitor whether the research is continuing to develop within the participants' expectations (Flewitt 2005). This comes with specific consent forms to be handed to participants at different times (video data collection, analysis, presentation, dissemination) (Hackling 2013; Wiles et al. 2008).

With children for whom consent from parents is mandatory, different informed consent models have been proposed. One is a two-stage consent: one for data collection (how data are collected, who collects, constraints on ultimate use) and one for the use (who will have access to which data, how, plans for data publication and destruction). The other is a graduated model providing a menu of uses to accept; for instance, viewing by the research team only, restricted sharing among research teams, presentation at professional meetings, full Web distribution (Derry et al. 2010). Informed consent forms can be restrictive or permissive: both bring advantages and disadvantages. Very permissive forms allow for unrestricted use of the videos but can reduce participants' willingness to participate. Conversely, restrictive forms limiting publication and promoting privacy might favour participants' involvement in the study (Derry et al. 2010; Schuck and Kearney 2006). A compromise which favours sharing appears to be the best solution (Derry et al. 2010, 40).

For children or participants with mental conditions (e.g. dementia), provisional consent can be negotiated with carers and participants (Puurveen, Phinney, and Cox 2015, 25), and revisited constantly during the research process (Robson 2011). With adolescents (14-16 years), we used both informed assent forms for adolescents' individual recordings and a collective negotiation of informed consent with all family members (parents, adolescents, and siblings or other co-habiting persons) before the recordings and after the discussion of findings which happened in a home visit with the whole family (Everri 2017; Everri, 2018).

Researchers should carefully consider the circumstances and adopt a flexible stance to meet participants' needs and settings' conditions (Wiles et al. 2012). For instance, in emergency medical interventions consent for video recording should be sought afterwards given the circumstances: time pressure and patients' and relatives' mental/emotional conditions might alter their capacities (Gelbart, Barfield, and Watkins 2009). In psychotherapy sessions, sensitive content can emerge during the video recording; therefore, an iterative negotiation of consent is preferable (Hutchby, O’Reilly, and Parker 2012).

In addition to obtaining previous consent that specifies the aims of the research, methodological procedures, and data management and dissemination, participants 
can be encouraged to review, edit, and delete portions of the recordings before the researchers have access to it, as in SEBE (Lahlou, Le Bellu, and Boesen-Mariani 2015). This, together with the collaborative interpretation between participant and researcher, the possibility to withdraw and destroy the data at any time, and the final disclosures about research results, creates in practice several instances of wellinformed consent.

Beyond target participants, researchers often need to obtain verbal or written consent by third parties or "the cast" (Lahlou 2017): family members, co-habitants, friends, colleagues, and so forth who willingly or not appear in the recorded scene. In this context, verbal permission recorded in the video or audio material itself is often an effective solution. In our research projects we asked participants to video record the moment in which permission is sought and given by third parties (Everri 2017; Lahlou 2017). While it is preferable to do that before the study commences for reasons discussed in the previous paragraphs, sometimes verbal consent can only be done on the spot - but that does not require recording the name of the cast, who can give anonymous (but recorded) consent. This solves a tricky issue: written informed consents need to be linked to the person on the film for blurring, etc., which unfortunately requires visual identification!

While privacy and anonymity of third parties must be protected and no identifying image should be published without their consent (Kelly et al. 2013; Lahlou et al. 2015), this condition must be balanced with reason and risk: in most cases that does not apply to passers-by in public space, where one expects to be seen in public. For instance, the ethical rules of TV industry about filming (e.g. BBC 2019) state that consent is not normally obtained from individuals who are incidentally caught on camera as part of the general scene. However, the right of individuals to ask to stop filming because of a concern of privacy is acknowledged unless it is editorially justified to continue.

In summary, informed consent in video research can be considered as a collaborative decision-making process (Banks and Zeitlyn 2015) negotiated among the present parties actively involved in the filming or acting as third parties (when asking consent is reasonably possible). It is an unfolding process and should thus be sought or confirmed at different stages of the research.

\section{Acknowledging participants' rights}

There seems to be some consensus in the literature about the need to clearly define and agree with participants the rules and procedures for the ownership and release of materials before data collection (Heath, Hindmarsh, and Luff 2010; Schuck and Kearney 2006; Cox et al. 2014; Mok, Cornish, and Tarr 2015; Gubrium, Hill, and Flicker 2014). This includes defining who has rights and access to the data, who can refuse access, for how long and for what purposes the data will be stored, what implications the release of the data might have, how and when it will be anonymised, how copies will be made, and which data will be available to other audiences and how (see Heath et al. 2010). Mok, Cornish, and Tarr (2015) discuss the 
need to limit the scale and scope of data capture in order to minimize risks and to limit the right of participants to possess and share materials. Schuck and Kearney (2006) recommend constructing multi-media documents and materials to report the research rather than publishing un-critical and un-edited materials. Special care must be taken with digital data that is easy to disseminate. In this vein, there has been an increasing use of data management plans.

As an example, management plans for SEBE video recordings (including automated self-recording) include information about a) the nature, type, approximate duration of data that can be collected, with examples; b) it should be specified that participants can forget they are wearing the device and record unwanted or unflattering images with examples provided (e.g., bathroom visits, online banking). Therefore, they should be clearly reminded to switch off the device or delete these scenes and how; c) participants should remove the device or temporarily pause image capture whenever they wish; d) participants should clearly understand that no individual will be identifiable in any research dissemination without their consent, therefore participants will have the opportunity to view (and delete if necessary) their images in privacy. e) Additionally, participants need to know that data concerning illegal activities may not be protected by confidentiality and may be passed to law enforcement depending on the national law and nature of the activity. f) Lastly, participants will not get copies of their images, only a team of specially trained researchers will have access to the image data (Kelly et al. 2013; Lahlou 2011). Nevertheless, in some cases a copy of the data is given to participants as a souvenir, provided they are made aware of the limitations to publication (Everri 2017).

Our research as well as other studies based on wearable devices for video recording everyday life situations (Kelly et al. 2013; Lahlou 2011) transfer part of the control over collection (filming) and management (review and deletion) of data to participants; nevertheless, the researchers must guarantee that ethical guidelines for research are followed still (Aarsand 2016).

Data management plans should provide a set of detailed measures as well as being open to revisions and inclusions of issues that emerge later: such discussions should be accommodated for in the protocol (for example during RIWs in the SEBE protocol). Pilot studies can also serve to test and refine data management plans as well as other aspects that should be included in informed consents (Everri, 2017).

The issue of data ownership can be particularly controversial here. Initially, participants are the owner of the data, who decide to share - by handing the recordings to researchers - their habits, practices, routines, places and spaces. The SEBE protocol empowers participants to exercise their rights of data ownership by allowing them to review and delete their own data, to decide what to share with researchers, and to review researchers' interpretations and comments on the collected material in the replay interview. Taken together, these practices acknowledge participants as the real expert. But once the data have been transferred to the researcher, the ethical responsibility is on the researcher. 


\section{The "ethical twist" for the future of visual ethnography}

This chapter examined the ethical challenges faced by ethnographers when dealing with visual data. Interestingly, one of the most often reported challenges is negotiating with academic research ethics committees. Those tend to be risk averse, especially when they are not familiar with a technique. Anecdotes include ethics committee members rejecting video protocols in fear of children using the equipment to record pornographic action, of birthday parties potentially turning into bullying sessions that would be recorded, and so forth. Reality is fortunately less wild than the imagination of some ethics committee members. Experienced ethics committees know that those researchers who made a good risk analysis of their protocol are usually also careful during the research. If necessary, committees should be reminded their role is not just to criticize but also to advise, and discussions should take place. For example, our team's ethical reflections were positively nourished by discussions with the ethics board at the London School of Economics, grounded in a systematic review of potential incidents and risks in 198 films (117.1 hours of video recording) made with the SEBE protocol. The discussion, despite challenging in the initial phases, proved to be an occasion to allow the LSE research ethics committee to review and update research ethics regulations including aspects related to video research brought to their attention.

Therefore, besides discussions with research ethics committees which is the cornerstone of any research ethics process, we believe the "ethical twist" for visual research is to consider those involved as participants in the research rather than subjects of observation, or informers. That "participatory twist" improves the quality of data collected through the trust obtained by transparency and participation. It also helps to solve the complex (and often emergent) issues arising from the disclosure of specific behaviours to other publics, with the informed help of the involved "natives", in the most culturally adapted way.

A risk analysis should be conducted; rather than trying to completely avoid risks, which is futile, it is useful to think of how to prevent them, and then what will be done in the rare case something does happen. Risk can often be dealt with by raised awareness, simple precautions, and quick adapted intervention when issues emerge. In automotive driving, active safety (having good brakes, etc.) is considered paramount, still one doesn't brake continuously. We advise the same on research: stay aware all along and be prepared to address emergent issues.

At a more operational level, while we are aware that fellow researchers would like a tick box list to show their ethics committee, we are convinced that each case is specific, and that tick box lists and templates do not foster the participative, reflexive exercise that we believe is necessary. For this reason, we have opted for the provision of a generic (but comprehensive) guide for each researcher to build their own ethical guidelines, procedures and cases for their ethics committee (see Table 5.1).

The "solutions" summarized in Table 5.1 have emerged from researchers' experiences, negotiations, mistakes and coping strategies. Bear in mind to adapt guidelines to the local context. Our experience taught us participants are the ones 
TABLE 5.1 Problems and proposed solutions for video research ethics

\begin{tabular}{|c|c|c|}
\hline $\begin{array}{l}\text { Problems / } \\
\text { critical issues }\end{array}$ & Description & Proposed solutions \\
\hline $\begin{array}{l}\text { Researcher- } \\
\text { researched } \\
\text { rapport }\end{array}$ & $\begin{array}{l}\text { Video research methods blur } \\
\text { researcher-researched boundaries } \\
>\text { Power imbalances }>\text { Ethical } \\
\text { issues on rapport }\end{array}$ & $\begin{array}{l}\text { Before commencing the study: } \\
\text { Apply contextual judgement } \\
\text { Practice reflexivity: consider multi- } \\
\text { ple stakeholders' perspectives } \\
\text { Consider participants as "research } \\
\text { collaborators" } \\
\text { Pilot study including some data } \\
\text { analysis discussion with participants }\end{array}$ \\
\hline $\begin{array}{l}\text { Informed } \\
\text { consent }\end{array}$ & $\begin{array}{l}\text { Collection of video recordings is } \\
\text { rarely pre-defined }>\text { Emergence of } \\
\text { new data from recordings in the } \\
\text { field }>\text { Ethical issues on dominant } \\
\text { "a priori bio-medical" informed } \\
\text { consent protocols }\end{array}$ & $\begin{array}{l}\text { Negotiate/renew consent at differ- } \\
\text { ent stages of the research } \\
\text { Involve children and parents in } \\
\text { consent negotiations (when children } \\
\text { are research participants) } \\
\text { Use video-recorded verbal consent } \\
\text { from third-parties (cast) }\end{array}$ \\
\hline $\begin{array}{l}\text { Participants' } \\
\text { rights }\end{array}$ & $\begin{array}{l}\text { Videos challenge participants' } \\
\text { privacy }>\text { Provide vivid details }> \\
\text { Easy to share }>\text { Ethical issues on } \\
\text { anonymity, confidentiality, own- } \\
\text { ership, and release of data }\end{array}$ & $\begin{array}{l}\text { Use data management plans: } \\
\text { Details participants' rights and duties } \\
\text { Be open to negotiate to reach a } \\
\text { balance between participants' pro- } \\
\text { tection and usability of the material } \\
\text { for scientific scopes } \\
\text { Make explicit arrangements in the } \\
\text { consent forms }\end{array}$ \\
\hline
\end{tabular}

who know their field best and can both point to potential issues and assess the validity of solutions. Having a transparent discussion with participants on the actual motives of the research, on how it will be used, and addressing candidly the potential problems are the best way forward, for ethical as well as heuristic reasons.

\section{Note}

1 Subjective Evidence-Based Ethnography is a digital ethnography methodology based on first-person perspective video recordings using an eye-level micro-camera mounted on glasses (Lahlou 2006a; Le Bellu et al. 2016; Glăveanu and Lahlou 2012; Lahlou 2010, 2011; Dieckmann et al. 2017; Mutinelli 2017; Jonassen 2016; Zhang 2015; Heptonstall 2015; Gobbo 2015; Evans 2015; Lahlou et al. 2015; Fauquet-Alekhine and Lahlou 2017; Stangeland 2016; Vrabcová 2015; Everri 2017).

\section{References}

Aarsand, P. 2016. "Children's media practices: Challenges and dilemmas for the qualitative researcher". Journal of Children and Media 10 (1): 90-97. https://doi.org/10.1080/ 17482798.2015.1121894

Aarsand, P., and L. Forsberg. 2010. "Producing children's corporeal privacy: Ethnographic video recording as material-discursive practice". Qualitative Research 10 (2): 249-268. 
American Anthropological Association. 2001. "AAA guidelines for the evaluation of ethnographic visual media”. AAA Statement. www.americananthro.org/ConnectWithAAA/ Content.aspx?ItemNumber=1941

Association of Social Anthropologists of the UK and the Commonwealth. 2011. "Ethical Guidelines for Good Research Practice". https://doi.org/10.1007/BF00753960

Atkinson, P. 2009. "Ethics and ethnography". Twenty-First Century Society 4 (1): 17-30.

Banks, M., and D. Zeitlyn. 2015. Visual Methods in Social Research. London: Sage.

BBC (British Broadcasting Association). 2019. "Editorial guidelines on privacy". BBC.co.uk. www.bbc.co.uk/editorialguidelines/guidelines/privacy/guidelines

Blazek, M., and P. Hraňová. 2012. "Emerging relationships and diverse motivations and benefits in participatory video with young people”. Children's Geographies 10 (2): 151-168. https:// doi.org/10.1080/14733285.2012.667917

British Sociological Society. 2017. "Ethics guidelines and collated resources for digital research". www.britsoc.co.uk/media/24309/bsa_statement_of_ethical_practice_annexe.pdf

Carroll, K. 2009. "Outsider, insider, alongsider: Examining reflexivity in hospital-based video research". International Journal of Multiple Research Approaches 3 (3): 246-263.

Carroll, K., and J. Mesman. 2018. "Multiple researcher roles in video-reflexive ethnography". Qualitative Health Research 28 (7): 1145-1156. https://doi.org/10.1177/1049732318759490

Cicourel, A. V. 1964. Method and Measurement in Sociology. Oxford: Free Press of Glencoe.

Clark, A., J. Prosser, and R. Wiles. 2010. "Ethical issues in image-based research". Arts E Health 2 (1): 81-93. https://doi.org/10.1080/17533010903495298

Cox, S., S. Drew, M. Guillemin, C. Howell, D. Warr, and J. Waycott. 2014. "Guidelines for ethical visual research methods". https://artshealthnetwork.ca/ahnc/ethical_visual_ research_methods-web.pdf

de Laat, S. 2004. "Picture perfect (?): Ethical considerations in visual representation". Nexus. The Canadian Student Journal of Anthropology 17 (1): Article 5. http://digitalcommons. mcmaster.ca/nexus/vol17/iss1/5/

Demuth, C., and M. Fatigante. 2012. "Comparative qualitative research in cultural psychology: Challenges and potentials". Zeitschrift für Qualitative Forschung 13 (1-2): 13-37.

Derry, S. J., R. D. Pea, B. Barron, R. A. Engle, F. Erickson, R. Goldman, R. Hall, et al. 2010. "Conducting video research in the learning sciences: Guidance on selection, analysis, technology, and ethics". Journal of the Learning Sciences 19 (1): 3-53. https://doi.org/10. 1080/10508400903452884

Dieckmann, P., M. Patterson, S. Lahlou, J. Mesman, P. Nyström, and R. Krage. 2017. "Variation and adaptation: Learning from success in patient safety-oriented simulation training". Advances in Simulation 2 (21): 1-14. https://doi.org/10.1186/s41077-017-0054-1

Eglinton, K. A. 2013. "Between the personal and the professional: Ethical challenges when using visual ethnography to understand young people's use of popular visual material culture". Young 21 (3): 253-271. https://doi.org/10.1177/1103308813488793

Evans, S. 2015. "Virtual selves in virtual worlds: Towards the development of a social psychological understanding of the self in contemporary society". PhD diss., London School of Economics, UK.

Everri, M. 2017. "Adolescents, parents, digital media: looking for the pattern that dis/connects". MSCA final research report. https://cordis.europa.eu/project/rcn/195993/factsheet/en

Everri, M. 2018. "La comunicazione familiare nell'era digitale." In Famiglie d'oggi. Quotidianità, dinamiche e processi psicosociali, edited by L. Fruggeri, 151-182. Roma: Carocci.

Fauquet-Alekhine, P. 2016. "Risk assessment for subjective evidence-based ethnography applied in high risk environment". Advances in Research 6 (2): 1-13. https://doi.org/10. 9734/AIR/2016/21597 
Fauquet-Alekhine, P., and S. Lahlou. 2017. "The Square of PErceived ACtion Model (SPEAC Model) applied in digital ethnography for work activity analysis: Performance and workers' perception". Current Journal of Applied Science and Technology 22 (312): 1-13. https://doi.org/10.9734/CJAST/2017/34985

Flewitt, R. 2005. "Conducting research with young children: Some ethical considerations". Early Child Development and Care 175 (6): 553-565. https://doi.org/10.1080/ 03004430500131338

Gelbart, B., C. Barfield, and A. Watkins. 2009. "Ethical and legal considerations in video recording neonatal resuscitations". Journal of Medical Ethics 35 (2): 120-124. https://doi. org/10.1136/jme.2008.024612

Glăveanu, V., and S. Lahlou. 2012. “'Through the creator's eyes': Using the subjective camera to study craft creativity”. Creativity Research Journal 24 (2-3):152-162. https://doi. org/10.1080/10400419.2012.677293

Gobbo, A. 2015. "The making of consumer decisions: Revisiting the notions of evaluation and choice by reconstructing consumer habits through subject evidence based ethnography”. PhD diss., London School of Economics, UK.

Gubrium, A. and K. Harper. 2013. Participatory Visual and Digital Methods. New York: Routledge.

Gubrium, A., A. L. Hill, and S. Flicker. 2014. "A situated practice of ethics for participatory visual and digital methods in public health research and practice: A focus on digital storytelling". American Journal of Public Health 104 (9): 1606-1614. https://doi.org/10. 2105/AJPH.2013.301310

Hackling, M. W. 2013. "Challenges of conducting ethical video-based classroom research challenges of conducting ethical video-based classroom research". ECU Publications Post, 1-5. http://ro.ecu.edu.au/ecuworkspost2013/839

Heath, C., J. Hindmarsh, and P. Luff. 2010. “Access, ethics and project planning”. In Video in Qualitative Research, 14-36. London: Sage Publications. https://doi.org/10.4135/ 9781526435385

Heptonstall, B. 2015. "Cognitive de-biasing strategies in medicine: A subjective evidencebased ethnography approach”. MSc diss., London School of Economics, UK.

Hutchby, I., M. O'Reilly, and N. Parker. 2012. "Ethics in praxis: Negotiating the presence and functions of a video camera in family therapy". Discourse Studies 14 (6): 675-690. https://doi. org/10.1177/1461445612457487

Jonassen, Z. 2016. "Good practices of replay interviewers: An explorative study of their understanding of the interview setting, attitude, and behaviour". MSc. diss., London School of Economics, UK.

Kelly, P., S. J. Marshall, H. Badland, J. Kerr, M. Oliver, A. R. Doherty, and C. Foster. 2013. "An ethical framework for automated, wearable cameras in health behavior research". American Journal of Preventive Medicine 44 (3): 314-319. https://doi.org/10. 1016/j.amepre.2012.11.006

Lahlou, S. 2006. "L'activité du point de vue de l'acteur et la question de l'Intersubjectivité : Huit années d'expériences avec des caméras miniaturisées fixées au front des acteurs (Subcam)". Communications 80: 209-234.

Lahlou, S. 2008. "Identity, social status, privacy and face-keeping in digital society". Social Science Information 47 (3): 299-330. https://doi.org/10.1177/0539018408092575.

Lahlou, S. 2010. "Digitization and transmission of human experience". Social Science Information 49 (3): 291-327. https://doi.org/10.1177/0539018410372020

Lahlou, S. 2011. "How can we capture the subject's perspective? An evidence-based approach for the social scientist". Social Science Information 50 (4): 607-655. https://doi. org/10.1177/0539018411411033 
Lahlou, S. 2017. Installation Theory. The Societal Construction and Regulation of Behaviour. Cambridge: Cambridge University Press. https://doi.org/10.1017/9781316480922

Lahlou, S., S. Le Bellu, and S. Boesen-Mariani. 2015. "Subjective evidence based ethnography: Method and applications". Integrative Psychological and Behavioral Science 49 (2): 1638. https://doi.org/10.1007/s12124-014-9288-9

Lahlou, S., S. Boesen-Mariani, B. Franks, and I. Guelinckx. 2015. "Increasing water intake of children and parents in the family setting: A randomized, controlled intervention using installation theory". Annals of Nutrition and Metabolism 66 (3): 26-30. https://doi.org/10. 1159/000381243

Le Bellu, S., S. Lahlou, V. N. Nosulenko, and E. S. Samoylenko. 2016. "Studying activity in manual work: A framework for analysis and training". Le Travail Humain 79 (1): 7-28. https://doi.org/10.3917/th.791.0007

Lenette, C., J. R. Botfield, K. Boydell, B. Haire, C. E. Newman, and A. B. Zwi. 2018. "Beyond compliance checking: A situated approach to visual research ethics". Journal of Bioethical Inquiry 15 (2): 293-303. https://doi.org/10.1007/s11673-018-9850-0

Liegl, M., and L. Schindler. 2013. "Media assemblages, ethnographic vis-ability and the enactment of video in sociological research". Distinktion: Scandinavian Journal of Social Theory 14 (3): 254-270.

London School of Economics and Political Science. 2019. "Research ethics: Guidance on LSE research ethics, code of research conduct, and training". https://info.lse.ac.uk/staff/ divisions/research-and-innovation/research/research-ethics/research-ethics

Markham, A., and E. Buchanan. 2012. "AOIR guidelines: Ethical decision making and internet research". www.aoir.org

Milne, E. J., C. Mitchell, and N. de Lange, eds. 2012. Handbook of Participatory Video. Lanham, MD: Rowman and Littlefield.

Mok, T. M., F. Cornish, and J. Tarr. 2015. "Too much information: Visual research ethics in the age of wearable cameras". Integrative Psychological and Behavioral Science 49 (2): 309-322. https://doi.org/10.1007/s12124-014-9289-8

Mudaly, N. 2015. "The rights of pre-verbal children involved in video-recorded research: An examination of the ethical issues". International Journal of Children's Rights 23 (2): 391-404. https://doi.org/10.1163/15718182-02302008

Mutinelli, S. 2017. "The psychology of waste: A subjective evidence-based ethnography for domestic activity". MSc. diss., London School of Economics, UK.

Nash, M., and R. Moore. 2018. "Exploring methodological challenges of using participantproduced digital video diaries in Antarctica". Sociological Research Online 23 (3): 589-605. https://doi.org/10.1177/1360780418769677

Papademas, D. 2004. "Editor's introduction: Ethics in visual research". Visual Studies 19 (2): 122-126. https://doi.org/10.1080/1472586042000301610

Papademas, D. 2009. "IVSA code of research ethics and guidelines". Visual Studies 24 (3): 250-257. https://doi.org/10.1080/14725860903309187

Pea, R. 1999. "New media communication forums for improving education research and practice". In Issues in Education Research: Problems and Possibilities, edited by E. C. Lagemann and L. S. Shulman, 336-370. San Francisco: Jossey-Bass.

Phelps, J. M., J. Strype, S. Le Bellu, S. Lahlou, and J. Aandal. 2018. "Experiential learning and simulation-based training in Norwegian police education: Examining body-worn video as a tool to encourage reflection". Policing (Oxford) 12 (1): 50-65. https://doi.org/ 10.1093/police/paw014

Pink, S. 2011. "Planning and practising 'visual methods': Appropriate uses and ethical issues". In Doing Visual Ethnography, 40-62. London: Sage Publications. https://doi.org/ 10.4135/9780857025029.d5 
Pink, S. H., H. Postill, J. Hjorth, T. Lewis, and J. Tacchi, 2016. Digital Ethnography. Principle and Practice. London: Sage Publications.

Pope, C. C., R. De Luca, and M. Tolich. 2013. "How an exchange of perspectives led to tentative ethical guidelines for visual ethnography". Ethics and Academic Freedom in Educational Research: 97-111. https://doi.org/10.4324/9781315872711

Prosser, J., A. Clark, and R. Wiles. 2008. "Working Paper \# 10 Visual research ethics at the crossroads". Crossroads 44 (November): 1-35.

Puurveen, G., A. Phinney, and S. M. Cox. 2015. "Ethical issues in the use of video observations with people with advanced dementia and their caregivers in nursing home environments". Visual Methodologies 3 (2): 16-26.

Rieken, J. C., and S. Lahlou. 2010. Theories, Protocols and Techniques Used to Elicit and Record the Production of Know-How by Experts. London: London School of Economics/ISP.

Robson, S. 2011. "Producing and using video data in the early years: Ethical questions and practical consequences in research with young children". Children and Society 25 (3): 179189. https://doi.org/10.1111/j.1099-0860.2009.00267.x

Rose, G. 2014. "On the relation between 'visual research methods' and contemporary visual culture". Sociological Review 62: 24-46.

Rouch, J., and E. Morin. 1961. Chronique d'un Été. France: Argos Films.

Ruby, J. 1991. Picturing Culture: Explorations of Film and Anthropology. Chicago: University of Chicago Press.

Salmons, J. 2015. Qualitative Online Interviews. Thousand Oaks, CA: Sage Publications.

Schembri, S., and M. V. Boyle. 2013. "Visual ethnography: Achieving rigorous and authentic interpretations". Journal of Business Research 66 (9): 1251-1254. https://doi.org/ 10.1016/j.jbusres.2012.02.021

Schuck, S, and M. Kearney. 2006. "Using digital video as a research tool: Ethical issues for researchers". Journal of Educational Multimedia and Hypermedia 15 (4): 447-463.

Stangeland, H. 2016. "Technology-enhanced learning in operative policing: Expert illustration videos and subjective evidence-based ethnography (SEBE) as learning tools among Norwegian police novices". MSc. diss., London School of Economics, UK.

Vrabcová, T. 2015. "I would never eat that back home. Analysing changes in food habits among Canadian and Chinese students in London: subjective evidence-based ethnography". MSc. diss., London School of Economics, UK.

Wiles, R., A. Coffey, and J. Robinson. 2010. "Anonymisation and visual images: Issues of respect, 'voice' and protection". International Journal of Social Research Methodology 15 (1): $41-53$.

Wiles, R., A. Coffey, J. Robison, and J. Prosser. 2012. "Ethical regulation and visual methods: Making visual research impossible or developing good practice?" Sociological Research Online 17 (1): 1-10.

Wiles, R., J. Prosser, A. Bagnoli, A. Clark, K. Davies, S. A. L. Holland, and E. Renold. 2008. "Visual ethics: Ethical issues in visual research". ESRC National Centre for Research Methods Review Paper 11. http://eprints.ncrm.ac.uk/421/

Wills, W. J., A. M. Dickinson, A. Meah, and F. Short. 2016. "Reflections on the use of visual methods in a qualitative study of domestic kitchen practices". Sociology 50: 470-485.

Winckler, M. 2014. "The temptation of documentation: Potential and challenges of videographic documentation and interpretation. a case-study from a civic education research project in Germany". Journal of Social Science Education 13 (1): 108-117.

Zhang, M. 2015. "How is the decision-making distributed in a complex dynamic system? An explorative study of air management teams in the intensive care unit using subjective evidence-based ethnography". MSc. diss., London School of Economics, UK. 